\title{
Research on Teaching Application of "Four-in-One" Teaching System in "Auditing" Course*
}

\author{
Dongchuan Lin \\ Sichuan Agricultural University \\ Chengdu, China \\ Manyu Wang \\ Sichuan Agricultural University \\ Chengdu, China \\ Changli Dai \\ Sichuan Agricultural University \\ Chengdu, China
}

\author{
Chen Ying** \\ Sichuan Agricultural University \\ Chengdu, China \\ **Corresponding Author \\ Jisheng Yi \\ Sichuan Agricultural University \\ Chengdu, China \\ Weilan $\mathrm{Fu}$ \\ Sichuan Agricultural University \\ Chengdu, China
}

\begin{abstract}
In order to achieve the coordinated development of the four specific objectives of the course "knowledge, ethics, ability, quality", so as to achieve the overall goal of training students' professional competence in auditing, this article proposes teaching innovation and practice from four aspects: curriculum knowledge system optimization, teaching and assessment methods reform, practical skills improvement, and resource platform construction based on the literature review of the teaching status, reform and innovation of the "Auditing" course, and combined with national talent strategy and industry needs, as well as changes in the practice environment and teaching environment.
\end{abstract}

Keywords-"Four-in-One"; Internet plus teaching; teaching community

\section{INTRODUCTION}

The 19th National People's Congress of the Communist Party of China proposed to firmly implement the strategy of invigorating the country through science and education, strengthening the country by talents and driving innovation. The Outline of the National Medium- and Long-Term Talent Development Plan (2010-2020) lists accounting talents as urgently needed talents for economic and social development. The Medium and Long-Term Talent Development Plan for Accounting Industry (2010-2020) and the 13th Five-Year Plan for Accounting Reform and Development propose to vigorously implement the accounting talent strategy and list CPAs as urgently needed talents in the industry which are short-handed. The revision of the "Accounting Law", the

*Fund support: This paper is supported by the key Project of Undergraduate Education and Teaching Reform Research of Sichuan Agricultural University in 2017(NO. X2017023), the Scientific Research Fund of Sichuan Vocational and Technical Education Center (NO. GZY18C51) and the funding of the Discipline Construction and the Academic Team Construction Program of Sichuan Agricultural University. international convergence of accounting standards and auditing standards, the wide application of big data auditing, and other changes in the practice environment and the Ministry of Education's "integration of production and education, collaborative education" mechanism construction, the rise of the "Internet plus teaching" model and other changes in the teaching environment make audit teaching reform imminent.

\section{CONOTATION OF "FOUR-IN-ONE" TEACHING SYSTEM}

In the "Four-in-One" teaching system, "One" means the overall goal of the audit teaching is to train the students ' auditing professional competency, and "Four" refers to the four specific goals of the course and four measures to achieve the goal. The four specific objectives ("Four goals") are the auditing theory knowledge goals, auditing professional ethics goals, auditing business skills goals, and comprehensive ability and quality goals. The four measures ("Four measures") are the optimization of the curriculum knowledge system, the reform of teaching and assessment methods, the improvement of practical skills, and the construction of teaching resources platform. The system is an organic unified system, "Four measures" to serve "Four goals" to achieve, "Four goals" unified in the overall goal, that is, the overall goal is achieved by relying on the organic combination of the "four measures" to promote the coordinated development of the "four goals".

\section{FEATURES OF "FOUR-IN-ONE" TEACHING SYSTEM}

\section{A. Strengthening Teaching Subject with the Concept of "Teaching Community"}

"Four in one" teaching system breaks through the single two-way interactive teaching system, the teaching subject 
will be extended by teachers and students to include teachers, students, schools, CPA associations, accounting firms, audit software companies and other teaching communities. Teachers are the main principals of teaching, they should be responsible for imparting the newest and most scientific theoretical knowledge to students, also should be familiar with the operation of the experimental software, instructing the students to operate the experiment, organizing the internship, and jointly guiding the students' practice with the association and the accounting firm, besides, they are responsible for the construction of teaching resources platform, enriching teaching resources and broadening students' learning channels. Students are the subject of learning, they should play the initiative and innovative spirit, consolidate theoretical knowledge, software operations, and actively participate in the practice of accounting firms, improve their professional quality. The school is responsible for deepening the cooperation mechanism with associations, accounting firms and auditing software companies, and assisting the construction of political, industry, university and research alliances. The CPA Association is mainly responsible for revising the standards, directing the teaching of audit theory, building a bridge between the school and the firm, relieving the contradiction between the supply side of the school auditing personnel training and the talent demand side of the accounting firm. The accounting firm mainly relies on providing the audit practice opportunity to support the practice teaching, enhances students' business ability. In addition, it is also responsible for feedback to schools on the new changes in the demand for talents in the industry and the ability defects reflected in the process of student practice, to promote teaching reform, and to accurately match the new demands of audit talents. The audit software companies are mainly responsible for better interfacing with the practical operation, enhancing the simulation and usability of the software, improving the students' interest in software operation, and increasing the students ' simulating business operation skills. In addition, in the audit teaching process, the parties need to work together, and pay attention to students' audit professional ethics, risk awareness and innovation ability.

\section{A. "Four Classes" Combine to Extend the Teaching Space}

"Four-in-One" teaching system will rely on classroom as the first class, laboratory as the second class, the CPA firm as the third class and network as the fourth class, so that we can construct "classroom space rotation, Interaction between the online and offline" three-dimensional classroom teaching mode. The first class emphasizes on students ' theoretical knowledge and professional ethics education, aimed at cultivating students ' professional quality and theoretical knowledge structure. The Second class focuses on training students ' simulation operation, software operation ability and primary practical skills. The third class puts emphasis on student' business training which is beneficial to students' practice ability and comprehensive professional quality. The fourth class is an important supplement to the other three classes. It focuses on the advantages of "Internet plus teaching" and students' subjective initiative, and extends the teaching class infinitely in space.

\section{B. Enhancing Professional Competence with "Four Goals" Coordinated Development}

"Four-in-one" teaching system strives to achieve the coordinated development of the "four goals" of ethics, knowledge, ability and quality around the core of the training of students' professional competency in the auditing field. As a national and socio-economic police, the auditing profession must first comply with financial regulations, auditing disciplines, auditing professional ethics and quality standards. Therefore, moral and risk education should be the primary objective of curriculum teaching. As a professional career, complete theoretical knowledge is the foundation of the auditing business. At the same time, the operability and technical of the auditing is also very prominent so that operation skills and practical ability are the key to unity of knowledge and practice. The rapid changes in the practical environment and the unbalanced nature of the actual situation also require the auditors to analyze specific problems and be innovative in complex situations. Therefore, the innovation-centered goal of comprehensive quality training is also an important task for auditing teaching to meet the requirements of new period.

\section{The "Four Measures" Organic Combination Helps the Realization of Teaching Goals}

"Four measures" in the teaching system of "Four-in-one" is an important support for the realization of teaching objectives. Scientific theory and practice have a guiding role. Therefore, continuously optimizing the knowledge system is an important measure to realize more scientific knowledge and better guide audit practice. The reform of teaching and assessment evaluation is a bridge for students to better grasp the scientific knowledge of auditing theory. Lacking of good teaching method, the scientific and complete theoretical knowledge system is only a "castle in the air" for students. At the same time, the reform of teaching and examination mode is not only an important measure for students to master the theoretical knowledge, but also a bridge to guide the auditing practice after the optimized theoretical knowledge. Practice is the only standard to test the real problem. The auditing theories only can play the value in the student' skill competition, the experiment operation, the business practice as well as the auditing work and other practical activities, therefore, around the improvement of practical skills, the framework of scientific and rational practice education system is an important part of audit teaching. The construction of the resource platform is an important supplement to break the time and space constraints, making full use of the advantages of "Internet plus teaching" and enrich the audit teaching activities.

\section{SugGestions ON THE CONSTRUCTION OF "FouR-IN- ONE" TEACHING SYSTEM}

\section{A. Continuous Optimization of Curriculum Knowledge System}

At present, the audit teaching mainly teaches the "Auditing" course based on the CPA examination textbook. The textbook knowledge system is organized around the 
audit of CPA, including four templates: audit theory, ethics and quality control, audit practice, and audit report. Lacking of a brief history of audit development, audit management system and other auditing common sense modules and CPA legal responsibilities, international convergence of auditing standards, big data auditing and other practice environment modules. Therefore, the author suggests to build a complete system of auditing knowledge covering six modules.

In addition, it is necessary to deal with the problem of continuous revision of auditing standards and stability of knowledge system. In 2014, The Ministry of Finance initiated the revision of the guidelines based on the accounting, auditing standards convergence strategy and the continuation of convergence roadmap. In 2016, the Ministry of Finance issued "Communication of Key Audit Matters in Audit Reports" and other 12 Chinese CPA Audit Standards (new audit reporting guidelines). In 2017, The application guide for new guidelines was issued. China's accounting and auditing standards will continue to be revised and perfected with the deep development of domestic and foreign capital markets and the revision of international accounting and auditing standards. Since the guidelines are the guidance documents for auditing teaching, after the revision of the guidelines, the teaching team should actively participate in the training of new standards organized by the National Accounting Institute to keep abreast of the latest developments and continuously optimize the knowledge points on the basis of maintaining the six main modules of auditing knowledge, ensuring that students are taught the latest knowledge.

\section{B. Reforming Teaching and Examination Methods}

On the basis of improving the quality of traditional teaching, teachers should pay attention to teaching feedback, constantly improve the current group-based collaborative discussion teaching, case teaching and other methods, and increase auditing classic reading and scenario simulation teaching. In the specific implementation, the students will conduct pre-class research and enrich the teaching method of "flip classroom". At the same time, according to the innovation of teaching methods, the curriculum assessment method is continuously optimized.

The goal of "Flipped class" is to change the students ' learning attitudes from passive condition to active situation, teachers ' teaching contents from a comprehensive foundation to a focus on key, so as to achieve the purpose of teaching and learning. First of all, in response to the general passive learning status of students, teachers enhance the students' initiative by cooperating with the student affairs department to carry out a series of activities. Secondly, teachers should actively adopt the "Internet plus teaching" model to guide students to make full use of the MOOC platform, the public platform of the resource sharing class of the Chinese university, and the self-learning basic knowledge of new media platforms such as Micro-blog, WeChat public number, and share the results of self-study. To test and consolidate basic knowledge, theoretical teaching focuses on key chapters. Finally, the "Flip Classroom" implementation form pays more attention to the characteristics of the lecture objects in addition to adopting the feedback from the students who have already taken the course.

\section{Enhancing Practical Skills}

Continuing to hold the auditing micro-film competition and organizing to participate in the "Ruihua Cup" National Campus Audit Elite Challenge are beneficial for students ' perception of auditing ethics and practice. We should strengthen cooperation with audit star, Ding Shin and other software companies, upgrade audit software, conduct better audit simulation experiment and enhance students ' operation skills. In addition, we need to make full use of the resources of Sihuan Provincial CPA Association, strengthen the cooperation with CPA firms, then put the audit practice into the post practice and graduation practice, and improve the students ' auditing practice ability. Finally, it constructs the three-level practice system of "perceptual cognitionsimulation experiment-firm practice", and helps students to improve their auditing practice skills.

Curriculum practice is the third level of practical skills upgrading, the school can collaborate with Sichuan Provincial CPA Association, accounting firms to communicate about "short-term plus long-term" internship plans further. The curriculum practices are recommended to be based on internal work and familiar with the audit working paper. Teachers and schools should fully mobilize the students to continue their internship in the firm. Students who participate in the field work during the winter vacation' internship will be preferred to recommend to the corresponding accounting firms including internship, graduation practice and employment to enhance the continuity of the internship. In addition, it is suggested that winter internship can be qualified to get credits of social practice of the winter vacation, calculating cumulatively the internship' time and graduation practice' time to motivate students to actively participate in the practice of the firm to enhance audit skills.

\section{The Construction of Teaching Resources Platform}

We are committed to publishing national textbooks as an editor-in-chief or coeditor according to the optimized knowledge system and continue to implement the multimedia courseware upgrading plan further and strive for the "audit" courseware in the Ministry of Education Multimedia Courseware Competition Award. We will enrich the case library, exercise library and question database resources and strengthen the functions of interactive new media platform such as micro-blog, WeChat public accounts and so on, and share teaching resources. Finally, we will sign more practice base of CPA firm and promote the construction of cooperative education mechanism.

\section{CONCLUSION}

In view of the present teaching situation of "attaching importance to theory rather than practice" in the Auditing course, this paper explores the application of "Four-In-One" teaching system in the teaching of Auditing, focusing on the goal of promoting students' audit practice, and some concrete 
measures are put forward in four aspects: optimizing the system of audit knowledge. Teaching reform, practical skill improvement and teaching resource platform construction. This research has certain practical significance for solving the theoretical and practical disjointed dilemma of audit teaching. The construction of teaching community is very critical to the implementation of this system, and the difficulties in its concrete implementation should not be ignored. Therefore, the system also needs to be combined with the practice of auditing teaching to improve continuously.

\section{REFERENCES}

[1] Jianghong Ye. Innovative Practice of Case Teaching in Auditing Courses [J]. Friends of Accounting, 2011 (3): 113-114.

[2] Xiaorong Yao. Some Thoughts on Improving the Quality of Audit Teaching[J]. Friends of Accounting, 2010(1):119-120.

[3] Ma Juan. Innovation and practice of teaching reform of accounting professional auditing course [J].China Management Informationization, 2010(13): 120-122.

[4] Jiajie Zhang. Study on University Audit Teaching Problems Based on New Criteria System [J].Accounting Newsletter, 2009(8) : 154-156.

[5] Qianghua Guo, Xuewen Chang, Pan Pan and Xuya Ye. Auditing Teaching Should Pay Attention to "National Auditing" [J]. Journal of Ningbo University, 2014(6): 80-83.

[6] Yanchao Rao, Jianyong Chen and Yuan Ye. Study on the Cultivation and Teaching of Computer Auditing Professionals[J]. Accounting Research,2008:84-87.

[7] Fanling Kong. Some Thoughts on Perfecting Audit Teaching[J]. Economist, 2010(6): 141-142.

[8] Xiangzhen Xu, Zhenfeng Chen and Lanfei Wu. Reform and Practice of Teaching Practice and Teaching Research in University Auditing in China[J]. Chinese Certified Public Accountant, 2013: 80-82.

[9] Guoxi Liu. Research on Application-based Undergraduate Audit Teaching Innovation, 2017(1):102-103. 